\title{
Stigma reduction in relation to HIV test uptake in low- and middle-income countries: a realist review
}

\author{
Subash Thapa ${ }^{1 *} \mathbb{D}$, Karin Hannes ${ }^{2}$, Margaret Cargo ${ }^{3}$, Anne Buve ${ }^{4}$, Sanne Peters ${ }^{5}$, Stephanie Dauphin ${ }^{5}$ \\ and Catharina Mathei ${ }^{5}$
}

\begin{abstract}
Background: This realist review was conducted to understand how stigma is reduced in relation to HIV test uptake in low- and middle-income countries (LMICs).

Methods: A systematic search of eight databases resulted in 34 articles considered for synthesis. Data synthesis was guided by a preliminary programme theory and included coding the meaning units to develop themes or intervention pathways that corresponded to context-mechanism-outcome configurations.

Results: We found that the interventions produced an effect through two pathways: (a) knowledge leads to changes in stigmatizing attitudes and increases in HIV test uptake and (b) knowledge and attitudes lead to changes in stigmatizing behaviours and lead to HIV test uptake. We also found one competing pathway that illustrated the direct impact of knowledge on HIV test uptake without changing stigmatizing attitudes and behaviour. The identified pathways were found to be influenced by some structural factors (e.g., anti-homosexuality laws, countryspecific HIV testing programmes and policies), community factors (e.g., traditional beliefs and practices, sexual taboos and prevalence of intimate partner violence) and target-population characteristics (e.g., age, income and urban-rural residence).
\end{abstract}

Conclusions: The pathways and underlying mechanisms support the adaptation of intervention strategies in terms of social context and the target population in LMICs.

Keywords: Context-mechanism-outcome configurations, HIV test uptake, Low- and middle-income countries, Realist review, And stigma reduction interventions

\section{Background}

According to the United Nations Programme on HIV/ AIDS (UNAIDS), there are approximately 37 million people worldwide living with HIV and almost $95 \%$ of people living with HIV (PLWH) reside in low- and middle-income countries [1]. Sub-Saharan Africa is the most affected region, with an estimated 26 million people living with HIV. An estimated $40 \%$ of people globally still need to access HIV testing service to know their HIV status, and the vast majority of them are in LMICs [2]. Where available, one of the reasons for

\footnotetext{
* Correspondence: soobesh@gmail.com; sthapa@health.sdu.dk

${ }^{1}$ Research Unit of General Practice, Department of Public Health, University of Southern Denmark, Odense 5000, Denmark

Full list of author information is available at the end of the article
}

the lower uptake of the HIV testing service in most LMICs is HIV stigma [3].

The Joint United Nations Programme on HIV/AIDS defined HIV stigma as a process of devaluation of people either living with or associated with HIV infection [4]. Stigma is both the behaviours of people without the disease (e.g., labelling, denial, exclusion) that leads to the devaluation of the people living or associated with HIV (public-stigma) and negative feelings of being devalued (e.g., fear, shame) among the people with the disease (self-stigma) [5]. PLWH have been stigmatized because the disease is generally perceived as dangerous, contagious, and associated with behaviours outside of social norms [6]. HIV stigma may have serious consequences, such as loss of friendship and family ties, dismissal from

(c) The Author(s). 2018 Open Access This article is distributed under the terms of the Creative Commons Attribution 4.0 International License (http://creativecommons.org/licenses/by/4.0/), which permits unrestricted use, distribution, and 
school and occupation, and denial of health care [7]. HIV stigma is associated with lower uptake of HIV testing services, non-disclosure and delayed entry into comprehensive health care, which further lead to higher transmission rates [3].

Several interventions to reduce HIV stigma have been developed and evaluated for their impacts on HIV test uptake. Some interventions have context-specific effects [8]. For example, interventions to increase access to HIV testing through a home-based testing approach in Kenya [9] and Zambia [10] were noted to reduce HIV stigma and increase HIV test uptake. However, an intervention based on mass media and interpersonal communication strategies in South Africa (2007) reported having some effect on HIV knowledge but limited effects on stigmatizing attitudes and HIV testing uptake [11]. An intervention, or set of interventions, may succeed or fail depending on the wider social systems in which they are implemented [12].

Stigma reduction interventions are complex. These interventions have multiple components: partly individual-related and partly resource-related [13]. The interaction between elements related to individuals and their sociocultural environment is a significant reason why HIV interventions succeed or fail [12]. For instance, individuals do not always make the same choices about their behaviours in a similar pattern every time. However, some choices (e.g., HIV testing) might be more likely than others depending on the opportunities and resources provided by the interventions.

Although individual behaviours and choices cannot be fully predicted, public health researchers can identify non-linear semi-predictable patterns of choice-making that occur under certain circumstances following an intervention. There is evidence showing that interventions have been effective in reducing stigma and increasing HIV test uptake; however relatively little is known on how, why, for whom and in which circumstances particular stigma reduction interventions work $[9,10]$.

\section{Why conduct this review?}

This review aims to address whether and how HIV stigma can be reduced to maximize public health benefits via increasing HIV test uptake in LMICs. Especially in LMICs, low income along with illiteracy and traditional beliefs may influence the association between stigma reduction and HIV test uptake [8]. Moreover, there is heterogeneity in the ways in which HIV stigma is experienced across different communities, and it is likely that the interventions and mechanisms that work to reduce HIV stigma and increase HIV testing may also vary between communities and individuals. The potential different pathways leading people to or pulling them away from HIV testing, thus, need to be unpacked [8]. Therefore, we conducted this realist review to understand how stigma is reduced in relation to HIV test uptake in LMICs.

The aim was to develop programme theory to uncover the mechanisms operating in stigma reduction interventions to increase HIV test uptake in particular contexts. A programme theory provides plausible explanations of why certain interventions work or do not work in certain circumstances [14]. Consequently, the underlying mechanisms would guide programme managers to design better public health interventions and understand which stigma reduction interventions should be implemented for whom and in which contexts.

\section{Methods}

A realist perspective was chosen because it allows for the evaluation of complex social interventions [15]. The realist perspective is a theory-driven and multi-method-based research methodology that uses an interpretive approach to synthesize evidence to reveal how intervention strategies interact with context to trigger mechanisms and produce outcomes. In a realist review, first, a preliminary programme theory is developed that explains how context influences mechanisms to generate outcomes. The preliminary theory is represented as a set of context-mechanism-outcome (CMO) configurations [15]. Then, the preliminary programme theory is iteratively refined based on a systematic review of empirical evidence to investigate whether, why or how intervention strategies produce observed outcomes, for whom and in what circumstances. The refined programme theory is a middle range theory that is useful for decision makers to identify "What works, for whom, in what respects, to what extent, in what contexts, and how?"

A middle range theory is understood as "theory that lies between the minor but necessary working hypotheses ... and the all-inclusive systematic efforts to develop a unified theory that will explain all the observed uniformities of social behaviour, social organization and social change" [16]. Pawson and Tilley argued that middle range theories are specific enough to generate particular propositions to test and are general enough to apply across different situations [12]. At best, a realist review can indicate the conditions in which the intervention works (or not) and how it does so, which allows programme managers and decision makers to assess whether interventions that proved effective in one setting may do so in another setting and assists programme planners in adapting interventions to suit specific contexts.

\section{Preliminary Programme theory}

This realist review was informed by a scoping review of empirical and grey literature on stigma reduction interventions to develop a preliminary programme theory (see Figure 1), which has been published elsewhere [8]. The scoping review resulted in an initial programme 


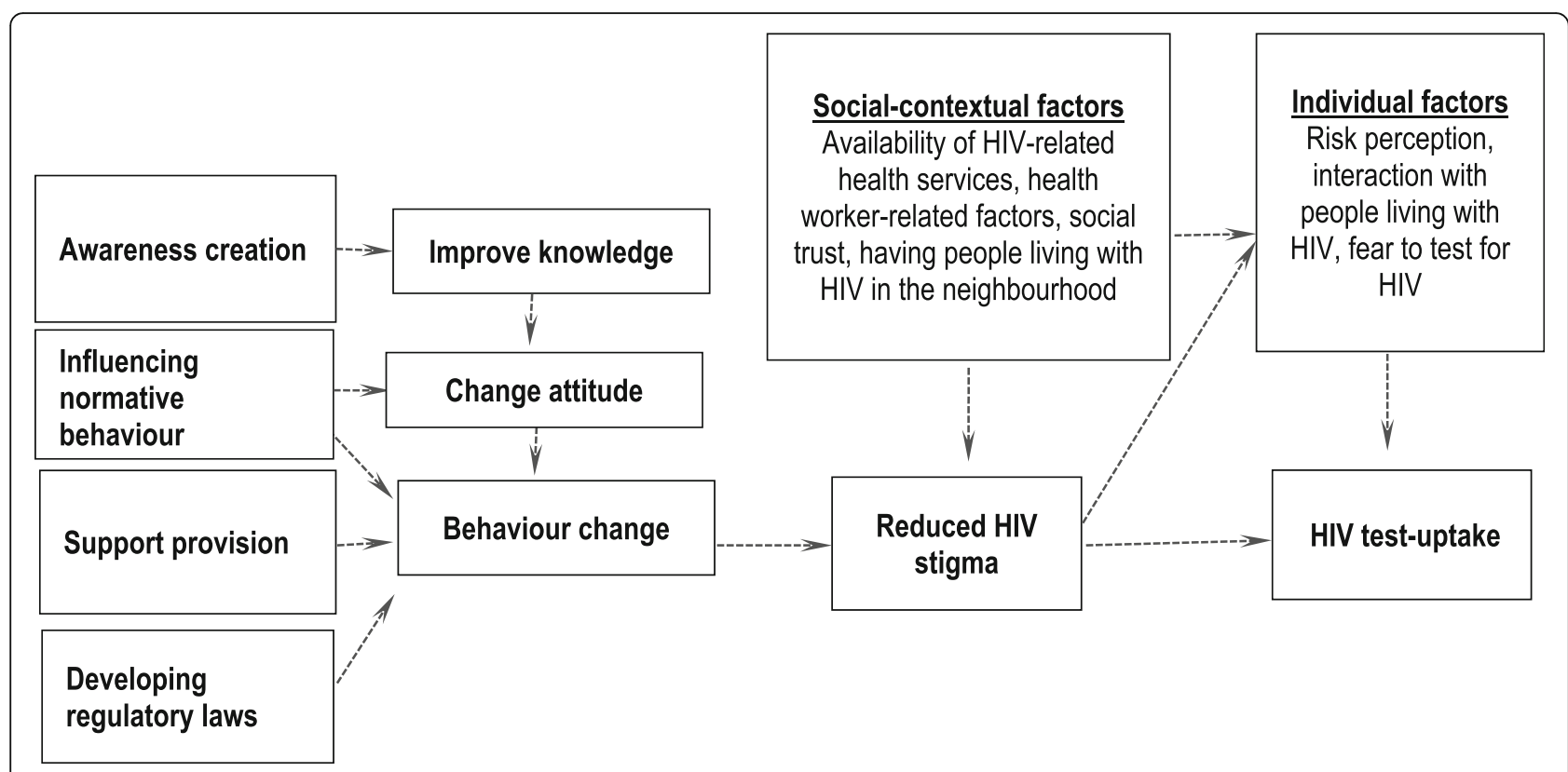

Fig. 1 Preliminary programme theory explaining the effect of stigma-reduction intervention strategies on HIV test uptake

theory consisting of 4 types of intervention strategies (i.e., awareness creation, influencing normative behaviour, providing support, and developing regulatory laws), three proximal outcomes (i.e., improvement of knowledge, change of attitude and behaviour) and one distal outcome (i.e., HIV test uptake). The preliminary programme theory conceptualizes HIV stigma as an overarching term that contains three elements: problems of knowledge (ignorance), problems of attitudes (prejudice), and problems of behaviour (discrimination) [17].

The awareness creation strategy generally improves knowledge about HIV and people diagnosed with HIV, and the influencing normative behaviour strategy changes stigmatizing attitudes and behaviours, and subsequently, increases HIV test uptake. Intervention strategies providing support to the people living or associated with $\mathrm{HIV}$, and developing regulatory law change the stigmatizing behaviours of the people, and subsequently, increase HIV test uptake. The framework further outlines that the mechanisms described are influenced by the interaction of various social-contextual and individual factors. Based on the initial scoping review, the following two research questions guided the review: (1) Does stigma reduction lead to HIV test uptake? (2) What are the pathways leading to HIV test uptake?

\section{Search strategy}

To bring together different sources of evidence that support, refine, or refute our preliminary programme theory, we performed a systematic search in the following eight electronic databases: PubMed, Excerpta Medica Database (EMBASE), POPLINE, PsycINFO, Sociological Abstracts,
Web of Science, Scopus and the Cumulative Index to Nursing and Allied Health Literature (CINAHL). We also performed an opportunistic purposeful searching process in 'Google scholar', 3ie database, trail registers from Campbell International Development Coordinating Group and the databases of two international organizations, namely the World Health Organization (WHO) and UNAIDS to enhance the possibility of identifying 'grey' literature [18]. Opportunities were sought to find additional studies from the reference list of primary studies.

\section{Screening and study selection}

We screened the articles in two phases. In the first phase, we included the articles based on the following core inclusion criteria: (a) dealt with HIV-related interventions that addressed causes of HIV stigma or included intervention components to reduce HIV stigma; (b) based in the low- or middle-income countries; (c) quantitative, qualitative or mixed-method studies, or programme reports and policy documents that described various forms of stigma or compared CMO configurations between different stigma reduction intervention strategies; (d) written in English; and (e) the outcome was related to HIV test uptake or for non-quantitative studies, the impact of stigma on HIV-test uptake was featured. The papers that were published until the year 2016 were considered for inclusion. Two independent reviewers screened the titles, abstracts and keywords of the identified documents.

In the second phase, the abstracts from the first phase were checked specifically against any one of the following three criteria: (a) whether the abstract described the 
association between stigma reduction and HIV test uptake, (b) whether the abstract referred to behaviour change relating to stigma reduction and HIV test uptake, and (c) whether the abstract described the social contextual factors influencing stigma reduction and its association with HIV test uptake.

Abstracts were coded as 'Yes' if any of the three-inclusion criteria were satisfied, and 'No' if none of the criteria were met. After the screening of abstracts for the second time, the full-text of articles were retrieved and evaluated by two independent reviewers to ensure that one or more of our inclusion criteria were met. Disagreements about articles to be included and excluded were resolved through consensus between the reviewers. Documents were included in the review based on relevance, that is, the extent to which they informed the development of the theoretical framework or clarified the CMO configurations [19].

\section{Data extraction}

For each included article, data were extracted independently by two researchers based on a data extraction tool. The contents of the preliminary programme theory were embedded in the data extraction form, and this provided a template to interrogate 'what works, for whom, in what circumstances'. To test the usability and functionality of the data extraction form, the tool was pretested on three purposefully selected articles [20]. The evidence table was designed to summarize the author/date, study aim, intervention, intervention strategies, study area, study type, population, outcomes, mechanisms involved, effectiveness and contextual factors for all the studies included. Direct quotations from qualitative studies were considered very informative and were accompanied by the name of the author and the year of the publication. The researchers compared and discussed their findings, and tried to reach consensus on the most important evidence presented in each article.

\section{Quality appraisal}

To assess the quality of primary studies, the Mixed Methods Appraisal Tool (MMAT)-Version 2011 (Department of Family Medicine, McGill University, Canada) was used. MMAT is one of the few tools that appraises the quality of diverse study designs [21] and provides a score that refers to the number of criteria met divided by four to calculate the percentage of the study quality for both quantitative and qualitative studies. For a mixed-methods study, the overall quality score is the lowest percentage of either the qualitative method or the quantitative method. We considered the score of $75 \%$ or above as 'high quality'. We did not make decisions to exclude any of the studies based on the study quality. We believed that the information about the study quality would complement the synthesis process by informing whether a particular inference drawn from a primary study was based on sufficient evidence to make a methodologically credible contribution to the theoretical framework [14]. Data from one study can be used to make sense of a pattern in another, and other sources may be used to build explanations [14].

\section{Data synthesis}

In this review, all the quantitative and qualitative data were analysed narratively. First, the data extracted from each study using the data extraction tool were summarized and organized in one evidence table (see Table 1). Extracted data from each primary study were coded for meaning units relevant to context, strategies, and mechanisms related to HIV test uptake. Next, themes were developed from the initial codes that corresponded to the preliminary theory. We then grouped several mechanisms, such as changed fear, changed shame, and increased tolerance of PLWH, according to the theme of attitudinal mechanisms (see Table 2). A focal point of the analysis was using the attitudinal mechanisms as a basis for constructing the context-mechanism-outcome pathways. For example, we identified the pathways as 'knowledge leading to changes in stigmatizing attitudes and increases in HIV test uptake' from assessing the relationships between the themes and considering the outcomes reported in the primary studies. The relationships between the themes were generated based on how the information was reported in the primary studies.

Identification and verification of the pathways followed an iterative process; connections were searched across data/themes to construct a cumulative picture. The generative mechanisms located within respective pathways were compared across similar and different contexts to identify if similar outcomes were generated and the preliminary programme theory could be improved. Finally, the preliminary programme theory was refined to reflect the generative mechanisms supported by evidence [22]. All interpretive processes were discussed and agreed upon among the co-authors of this review.

\section{Results}

Figure 2 shows the flow of work processes from the database selection to the screening processes and the final selection of primary studies. Searches for articles yielded 5528 records that were culled to 3361 records after removing duplicates. Abstracts were appraised for relevance against the inclusion criteria in the initial screening. A total of 815 articles were considered for a second screening. After the second screening, 67 articles were considered for a full text appraisal for relevance and resulted in 34 articles being retained for the synthesis. 


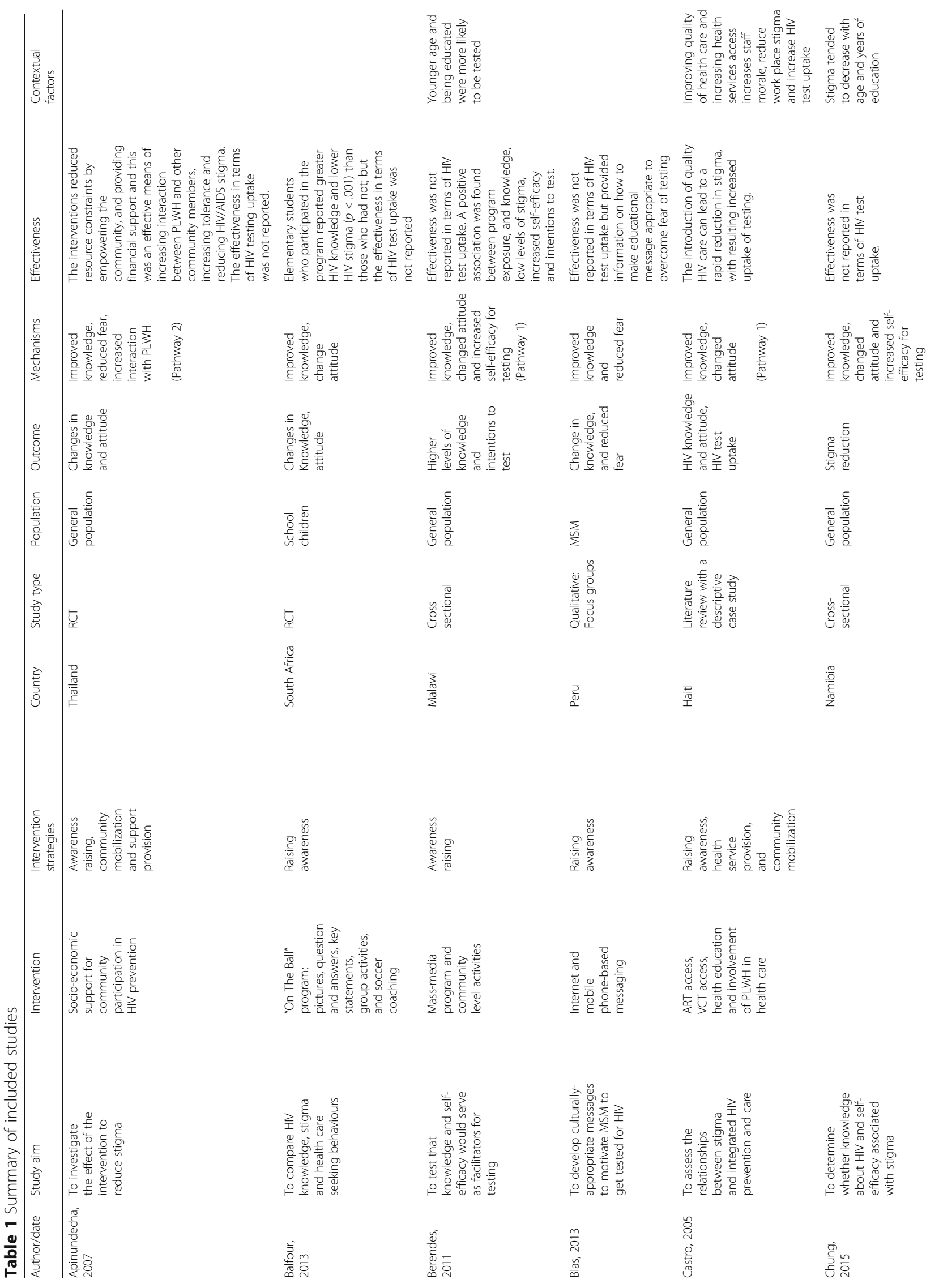




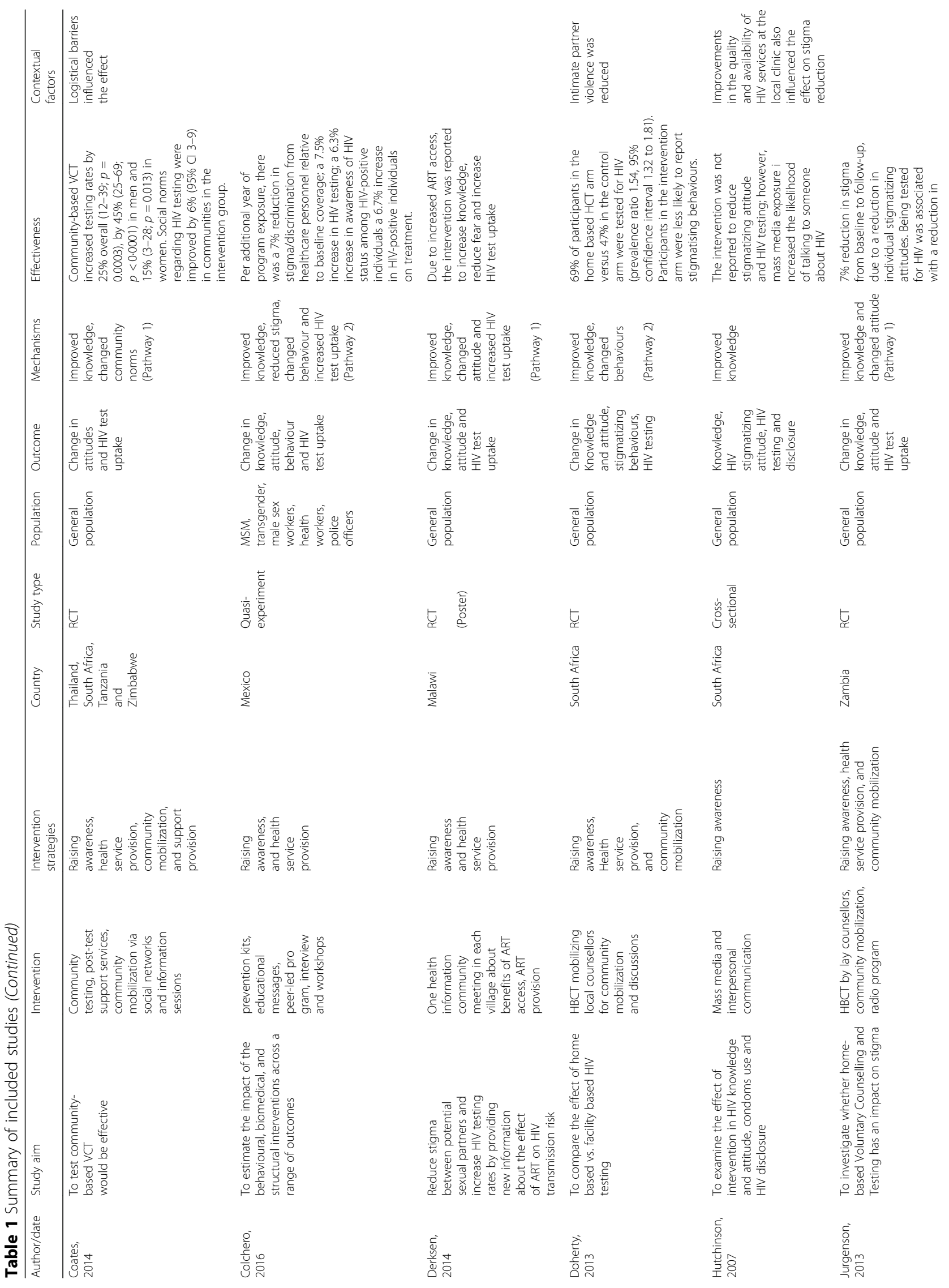




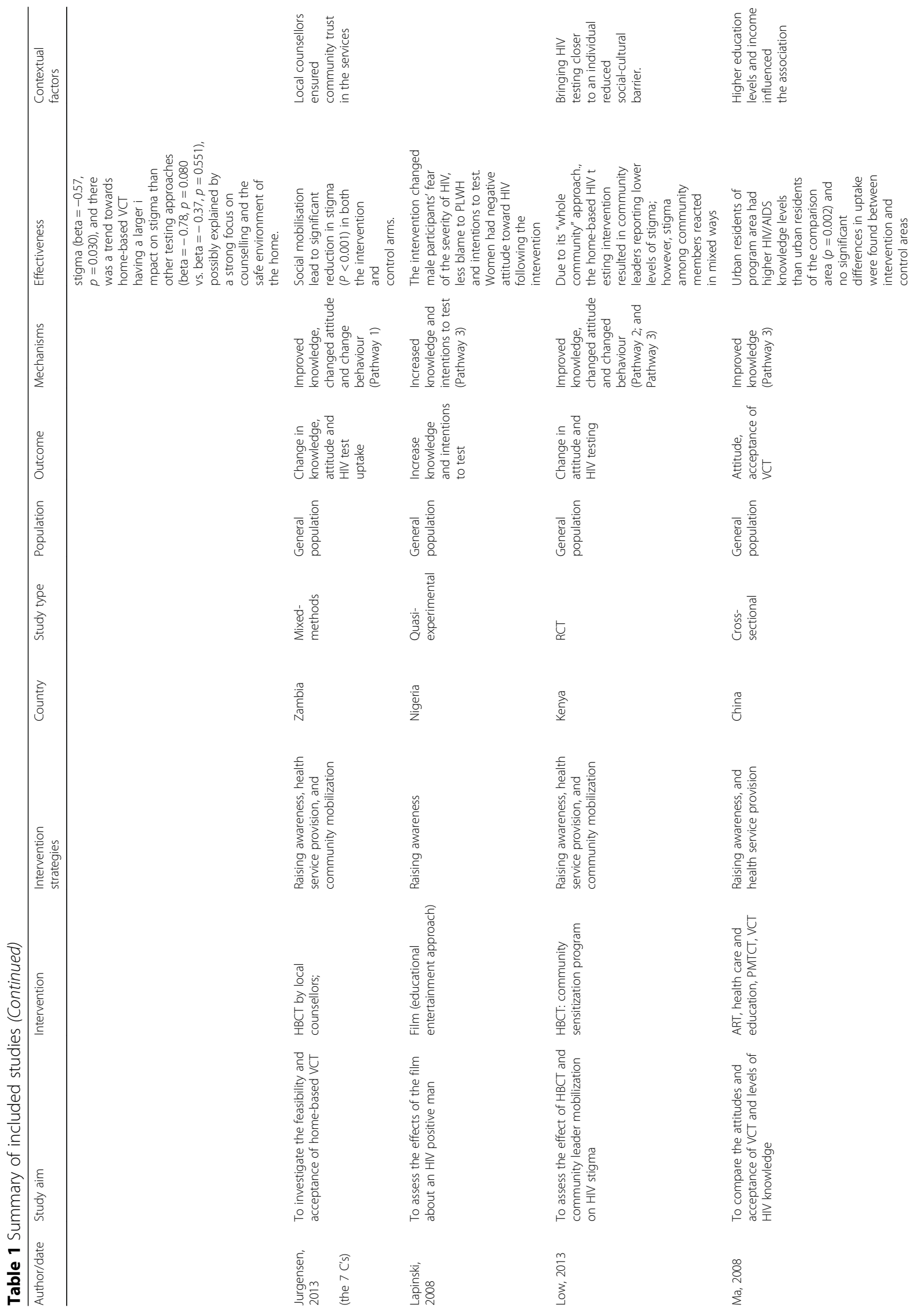




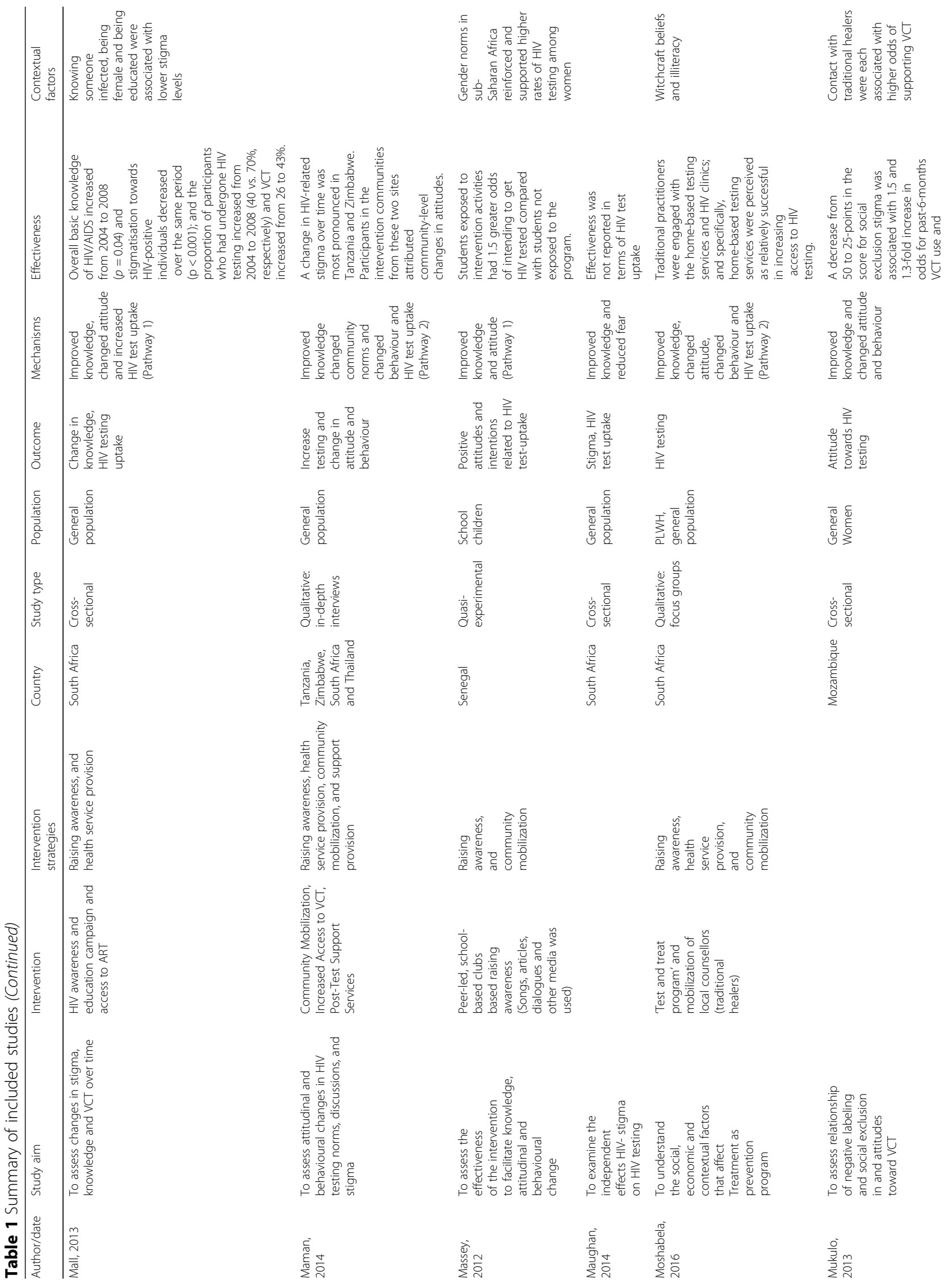




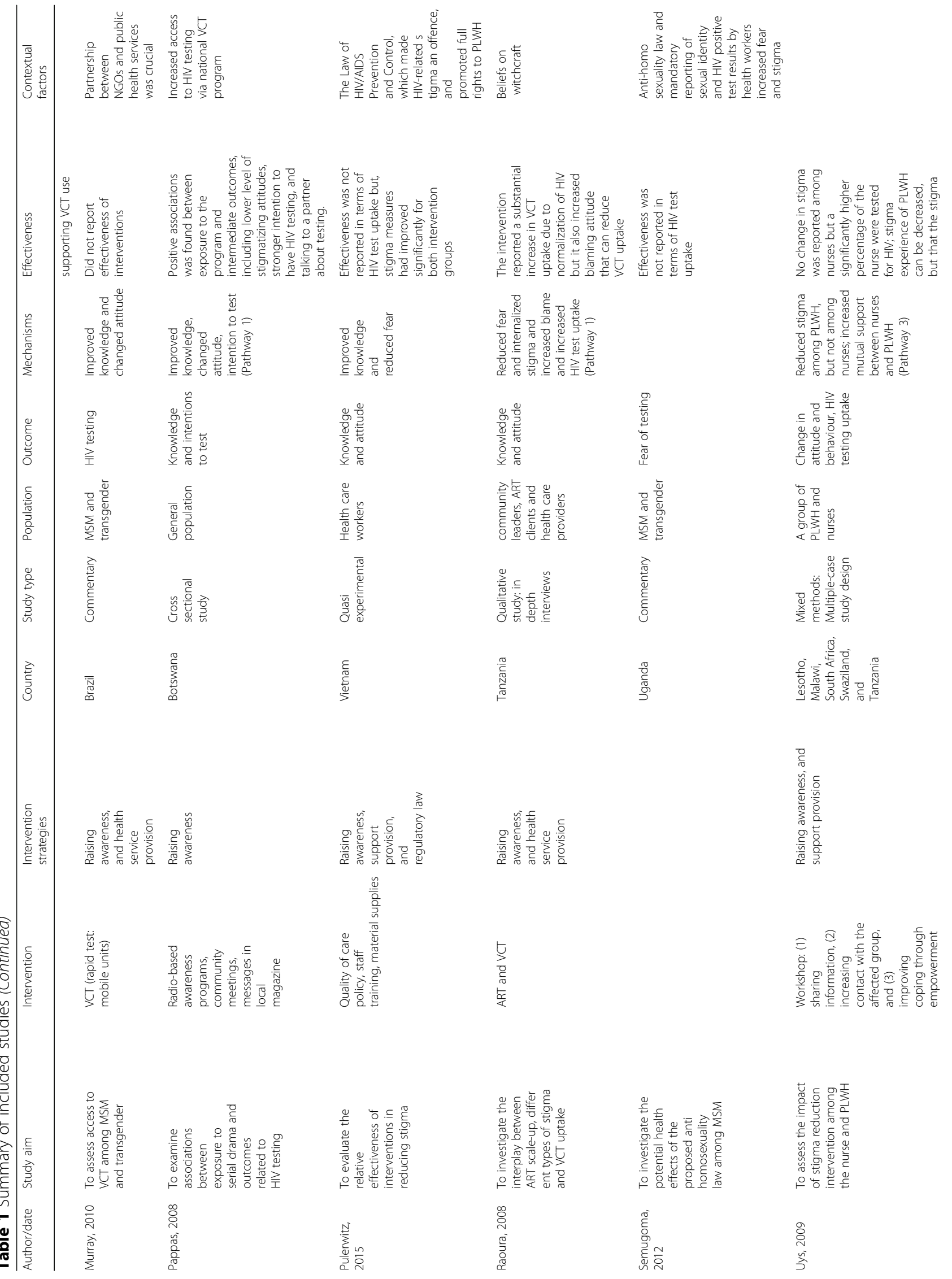




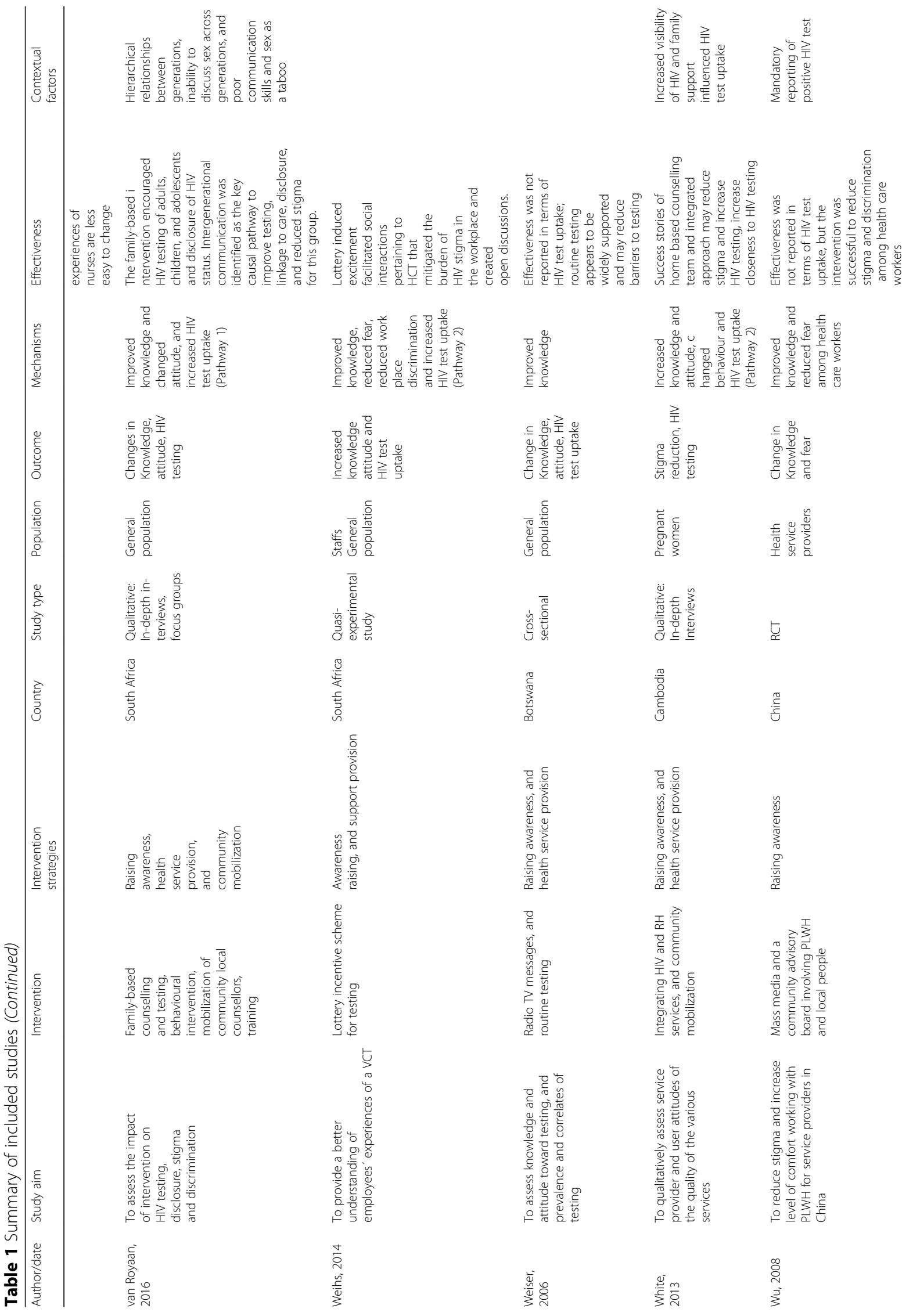




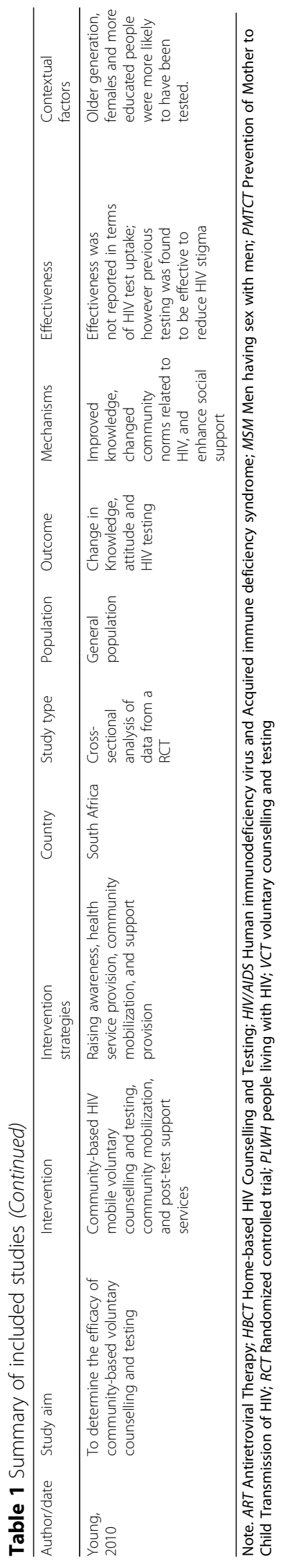


Table 2 Coding tree for identifying several mechanisms and pathways for stigma reduction and HIV test uptake

\begin{tabular}{|c|c|c|}
\hline Categories & Themes & Codes \\
\hline \multirow{4}{*}{$\begin{array}{l}\text { Contextual } \\
\text { factors }\end{array}$} & Structural factors & Homosexuality legislation, voluntary or mandatory reporting policies \\
\hline & $\begin{array}{l}\text { Health system } \\
\text { factors }\end{array}$ & $\begin{array}{l}\text { Health care quality and access, higher staff morale, effective referral, confidentiality, ongoing national } \\
\text { health programs, discrimination at health care, increased partnership with community organizations }\end{array}$ \\
\hline & $\begin{array}{l}\text { Community } \\
\text { factors }\end{array}$ & $\begin{array}{l}\text { Social support, traditional beliefs and practices, gender norms, peer pressure, family testing, PLWH in the } \\
\text { neighbourhood, gender-based violence, resource constraints, communication gap in the family } \\
\text { (sexual taboo), }\end{array}$ \\
\hline & Individual factors & $\begin{array}{l}\text { Previous history of testing, gender, age, education, income, distance to health centre, urban-rural } \\
\text { residence, increased risk-perception, self-confidence, higher self-esteem, intentions to test, trust in } \\
\text { health care }\end{array}$ \\
\hline \multirow[t]{5}{*}{$\begin{array}{l}\text { Stigma Reduction } \\
\text { Intervention } \\
\text { Strategies }\end{array}$} & Awareness & $\begin{array}{l}\text { Radio TV messages, mass media and interpersonal communication, film, health education program, } \\
\text { role plays, group discussions, HIV advocate testimony, presentation, workshop, questions and answers, } \\
\text { mobile phone messaging, training, motivational interviews, peer education }\end{array}$ \\
\hline & $\begin{array}{l}\text { Public health } \\
\text { services }\end{array}$ & $\begin{array}{l}\text { ART, opt-out testing, prevention from mother to child transmission, VCT, mobile VCT, home based VCT, } \\
\text { Integrating HIV and RH services, community testing, family based testing and counselling, } \\
\text { involvement of PLWH in the intervention }\end{array}$ \\
\hline & $\begin{array}{l}\text { Community } \\
\text { mobilization }\end{array}$ & $\begin{array}{l}\text { Child clubs, mobilization of community local counsellors, discussion with community leaders, } \\
\text { mobilization of traditional health practitioners }\end{array}$ \\
\hline & Support & $\begin{array}{l}\text { Socio-economic support for community participation, contact with affected group, improving coping } \\
\text { skills through involvement and empowerment, post-test support services, incentives }\end{array}$ \\
\hline & Regulatory laws & $\begin{array}{l}\text { Formation of hospital steering committee to oversee quality of care, hospital (confidentiality) policy } \\
\text { development, material supply for practicing universal precautions, providing incentives for testing }\end{array}$ \\
\hline \multirow[t]{3}{*}{$\begin{array}{l}\text { Mechanisms of } \\
\text { stigma reduction }\end{array}$} & $\begin{array}{l}\text { Increase } \\
\text { knowledge }\end{array}$ & $\begin{array}{l}\text { Knowledge about HIV is manageable, prevention measures, changed negative beliefs, changed } \\
\text { community norms, normalization, knowledge about universal precautions, changed sexual taboo }\end{array}$ \\
\hline & $\begin{array}{l}\text { Change } \\
\text { attitude }\end{array}$ & $\begin{array}{l}\text { Reduced fear (self-stigma), reduced perceived stigma (shame and worrisome), acceptance of testing } \\
\text { services, increased tolerance and comfort with PLWH in variety of situations, acceptance of PLWH; } \\
\text { respect for confidentially among health workers, less endorsement of policies to separate PLWH }\end{array}$ \\
\hline & Change behaviour & $\begin{array}{l}\text { Comfort, interaction of PLWH in the community, lower tendencies to exclude PLWH, less blame, } \\
\text { reduced enacted stigma experiences, involving PLWH in the community, encouraging others to test }\end{array}$ \\
\hline \multirow[t]{2}{*}{ Outcome } & $\begin{array}{l}\text { Proximal } \\
\text { outcomes }\end{array}$ & $\begin{array}{l}\text { Improved knowledge, reduced fear, reduced shame, reduced blame, reduced discrimination } \\
\text { and increased interaction }\end{array}$ \\
\hline & Distal outcomes & HIV test uptake, self-efficacy and intentions to test for HIV \\
\hline
\end{tabular}

Note. PLWH people living with HIV; VCT voluntary counselling and testing

\section{Study and intervention characteristics}

Table 3 illustrates the study and intervention characteristics. From a total of 34 articles, 10 were cross-sectional studies, 8 were randomized controlled trials, 6 were qualitative, 5 were quasi-experimental, and 2 were a mixed-methods study (see Table 1). In addition, 1 article was a literature review and 2 were commentaries published in scientific journals. Regarding study quality based on the MMAT, approximately $68 \%$ of the articles were rated high quality. Two commentaries and one poster did not have clear research questions and methodological details, and therefore, were not assessed for study quality.

There were 4 non-intervention studies [23-26] and 30 intervention studies. From a total of 30 intervention studies, most of the interventions were conducted in Africa (19), followed by Asia (5), South America (3), and North America (1). Three were multi-country interventions conducted in Lesotho, Malawi, South Africa, Tanzania, Zimbabwe and Thailand [27-29].

The proximal outcomes reported in all the intervention studies were: improved knowledge or changed attitude or changed discriminatory behaviour. The reported distal outcome was HIV testing uptake in 24 interventions studies and the remaining 6 intervention studies [30-35] measured either self-efficacy or intentions to test or both as distal outcomes. In these intervention studies, self-efficacy and intentions to test were conceptualized as proximal predictors of HIV test uptake. However, none of these studies suggested how self-efficacy and intentions lead to HIV testing uptake. Since our primary aim was to identify and verify the pathways and mechanisms of stigma reduction in terms of HIV test uptake, self-efficacy and intentions to test were not considered as outcomes in this review. HIV testing was mostly assessed by asking the study participants whether they had an HIV test within 12 months after the intervention. In the qualitative studies, participants were asked to explain their most recent HIV testing experience.

Among the 30 articles reporting interventions aimed at reducing stigma (in terms of attitudinal mechanisms), 15 interventions reported increases in HIV testing uptake, 8 reported reduction in stigma but did not report 


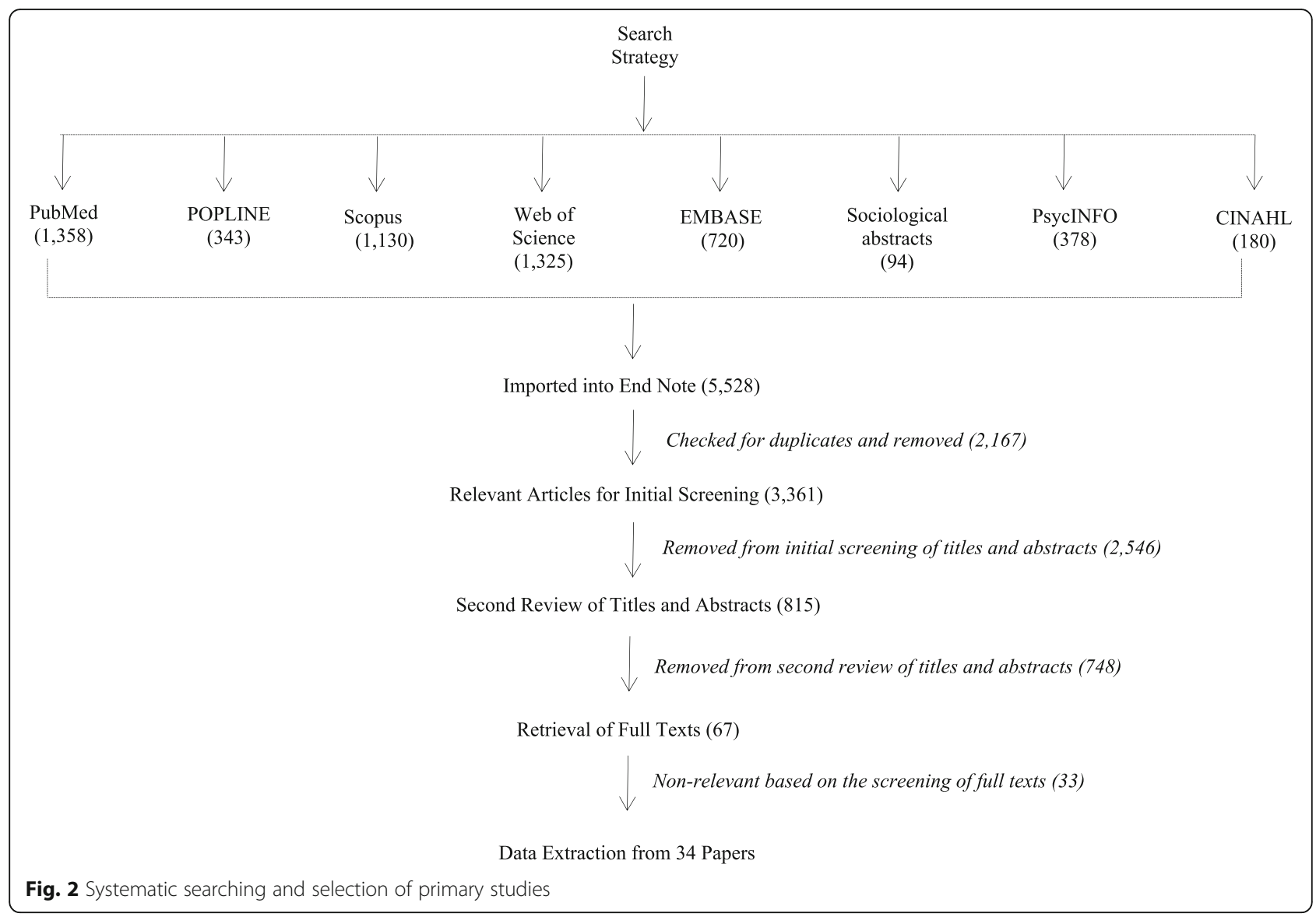

effectiveness in terms of HIV test uptake, 4 reported increases in self-efficacy or intentions to test and 3 reported interventions being ineffective to reduce stigma and increase HIV testing uptake.

\section{Stigma reduction intervention strategies}

Our synthesis of all selected articles explained how stigma reduction interventions were implemented in relation to the opportunities or challenges provided by the contextual forces to increase HIV test uptake (see Fig. 3). The synthesis revealed five different intervention strategies that were included in the stigma reduction interventions, which are explained below:

\section{Awareness raising strategy}

The awareness raising strategy included HIV-specific fact-based written or verbal information, communication, and education as major components. This strategy was aimed at increasing knowledge, and changing attitude and behaviours. The awareness raising components in the interventions were: radio messages, printed mass media, interpersonal communication, films, health education programmes, role plays, group discussions, HIV advocate testimonies, presentations, workshops, questions and answers, mobile phone messaging, training, motivational interviews and counselling. All the interventions included in this review had the awareness raising strategy.

\section{Health service provision strategy}

The health service provision strategy included providing HIV-related services for the betterment of PLWH and the prevention of HIV infection in the community. This strategy reduced barriers related to health service access and logistics to increase HIV test uptake. The health services that were provided in the interventions were: anti-retroviral therapy (ART), routine health test without an informed consent (also called opt-out testing), availability of anti-retroviral drugs to mothers and their newborns, safe childbirth, infant feeding counselling, voluntary counselling and testing (VCT), mobile VCT, home-based VCT, family-based VCT, community VCT and other reproductive health services. Altogether, 18 interventions provided any of these health services, and 15 of them provided VCT services.

\section{Community mobilization strategy}

The community mobilization strategy involved local counsellors at the local community-level to enhance community organizing initiatives to raise awareness, 
Table 3 Study and intervention characteristics

\begin{tabular}{|c|c|c|}
\hline Characteristics & Number of studies & Percent (\%) \\
\hline \multicolumn{3}{|l|}{ Study types } \\
\hline Randomized controlled trial & 8 & 23.5 \\
\hline Quasi-experimental & 5 & 14.7 \\
\hline Cross-sectional & 10 & 29.4 \\
\hline Qualitative & 6 & 17.7 \\
\hline Mixed-methods & 2 & 5.9 \\
\hline Literature review & 1 & 2.9 \\
\hline Commentaries & 2 & 5.9 \\
\hline \multicolumn{3}{|l|}{ Study Quality } \\
\hline $100 \%$ & 13 & 38.2 \\
\hline $75 \%$ & 10 & 29.4 \\
\hline $50 \%$ & 6 & 17.7 \\
\hline $25 \%$ & 2 & 5.9 \\
\hline Not applicable & 3 & 8.8 \\
\hline \multicolumn{3}{|l|}{ Intervention characteristics } \\
\hline Interventional studies & 30 & 88.2 \\
\hline Non-intervention studies & 4 & 11.8 \\
\hline \multicolumn{3}{|c|}{ Location of interventions $(n=30)$} \\
\hline African countries & 18 & 60.0 \\
\hline South American countries & 3 & 10.0 \\
\hline Asian countries & 5 & 16.7 \\
\hline North America & 1 & 3.3 \\
\hline Multi-country & 3 & 10.0 \\
\hline
\end{tabular}

change behaviours and provide health service to the community people. The local counsellors were traditional healers, youth counsellors, community health workers, local community leader or local facilitators. In the interventions, the mobilization of local counsellors was performed in the following activities: to organize community meetings on benefits of ART, to provide general information about HIV and HIV testing, to provide training to community leaders on ART and VCT, to work as a member of a community group that engages people in raising awareness of HIV, to perform HIV counselling and testing and to refer to the health clinic for standard testing and care. Altogether, 13 interventions had the community mobilizing strategy.

\section{Regulatory law strategy}

The regulatory law strategy included incorporating HIV-related legislation to protect and respect the human rights of PLWH. None of the interventions included in this review were based on regulatory law strategy. Only one intervention was based on developing policies related to confidentiality and respect of the rights of PLWH and formation of a hospital steering committee to oversee the quality of care. This intervention was implemented only in four hospitals of Vietnam, targeting the health workers [36].

\section{Support provision strategy}

The service provision strategy included providing social and psychological support to PLWH through teaching coping skills, directly contacting people associated with HIV and the friends or neighbours of PLWH and involving them in community development initiatives or health care and providing incentives or material support to the community people to access HIV-related services. Altogether, 7 interventions had the support provision strategy.

In total, 23 intervention studies had combined more than one strategy. Among the 23 combination interventions, 15 reported increases in knowledge and attitude leading to HIV testing uptake. A total of 8 combination

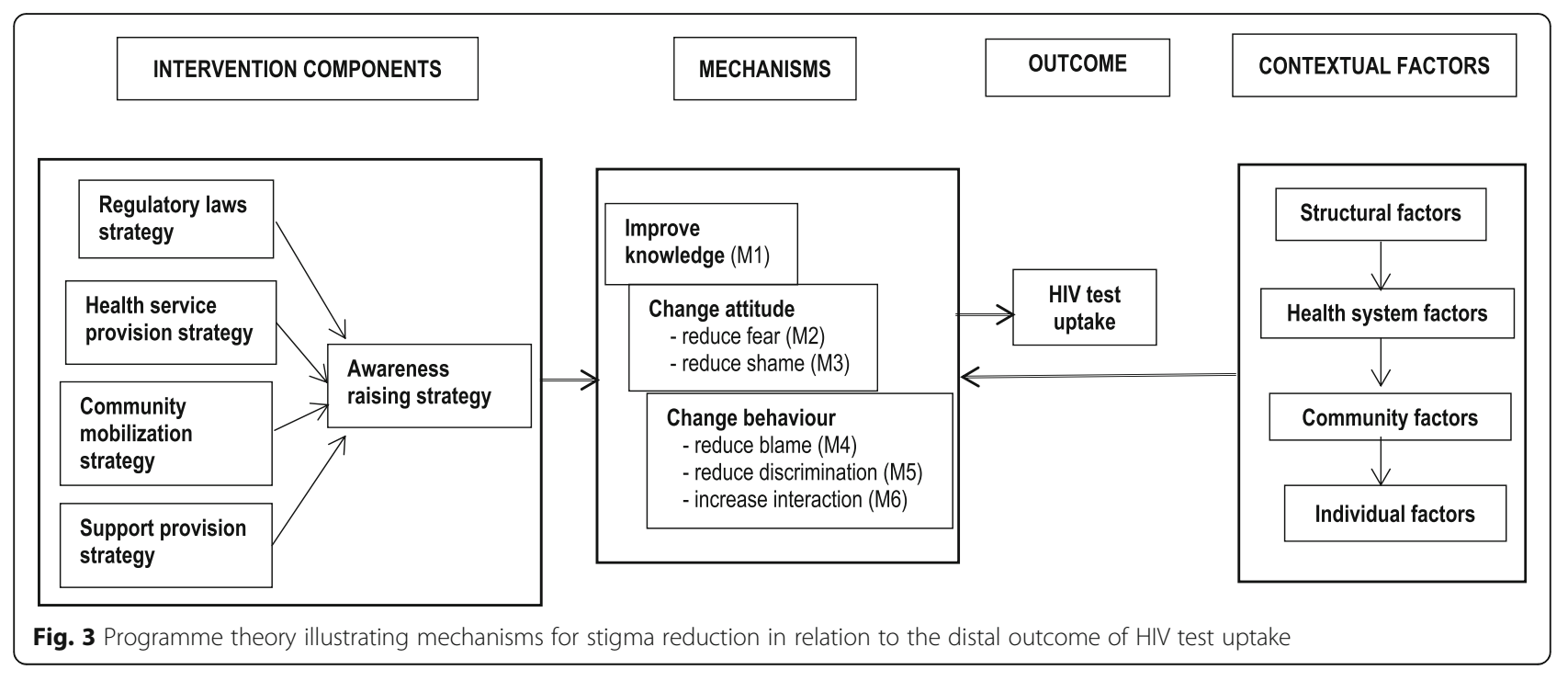


interventions integrated awareness raising, health service provision and community mobilization strategies. Unlike the 23 combination interventions, the remaining 7 singular interventions had only the awareness raising strategy. From these 7 studies, 5 reported HIV testing uptake as an outcome, and 3 of the 5 studies reported increases in HIV test uptake via increasing knowledge and changing attitude [32, 33, 37].

\section{Mechanisms of stigma reduction in relation to HIV test uptake}

Our synthesis of the evidence found six different mechanisms that were operating in stigma reduction interventions in relation to HIV test uptake, which were interlinked in three dominant pathways (See Figure 4). Pathway 1 and Pathway 2 illustrate the importance of knowledge in reducing stigmatizing attitudes and discriminations, whereas Pathway 3 illustrates the independent effect of knowledge on increasing HIV test uptake. These pathways were determined by the components of the interventions and the population group that were targeted by the stigma reduction interventions. Figure 4 only represents the pathways leading to increased HIV test uptake, and some inhibitory pathways are articulated narratively.

\section{Pathway 1: Knowledge leads to changes in stigmatizing attitudes to increase HIV test uptake}

Pathway 1 indicates the pivotal role of knowledge (Mechanism 1; is abbreviated as 'M1') to trigger attitudinal mechanisms and increase HIV testing uptake. The attitudinal mechanisms triggered by knowledge were reduced fear (Mechanism 2; is abbreviated as 'M2') and reduced shame (Mechanism 3; is abbreviated as ' $\mathrm{M} 3$ '). Among the 22 intervention studies reporting increases in HIV test uptake, 11 of them [10, 27, 33, 35, 37-42] reported following Pathway 1, and 10 of 11 interventions were conducted in African countries (see Table 3). Interventions that followed Pathway 1 to increase HIV test uptake mostly had awareness raising as a singular strategy or had a combination of awareness raising and health service provision strategies and were targeted to the general population.

\section{Improved knowledge}

Increases in knowledge were found to be the most common element to increase HIV test uptake in all the interventions. Altogether, 4 combination interventions (2 in African countries, 1 in multiple countries and 1 in Haiti) having awareness raising, community mobilizing and health service provision strategies were found to follow 'Pathway 1' to increase HIV test uptake [10, 27, 38, 41]. These interventions provided HIV testing and counselling services based on a 'home-based door to door approach' or a 'whole community approach', meaning that these interventions targeted all members of the community. This approach was noted to reduce the chances of being singling out from the mainstream health system among the vulnerable and hard-to-reach population groups and increased their participation in HIV testing services. In the study by White (2013), one of the participants from Cambodia mentioned [43]:

\begin{abstract}
"The local NGOs ... visit once a month. They ask questions about my health.. . whether we are well or not, whether I take medicine regularly or not. I tell them that I take medicine every day. Home-based counselling and testing team also advises on the prevention of HIV transmission, including condom use".
\end{abstract}

Two interventions based on the awareness raising strategy noted a positive association between the programme exposure and knowledge, reduced stigma and increases in self-efficacy or intentions to test in Botswana and Malawi [30, 33]. Both interventions had multiple awareness raising components (e.g., radio-based

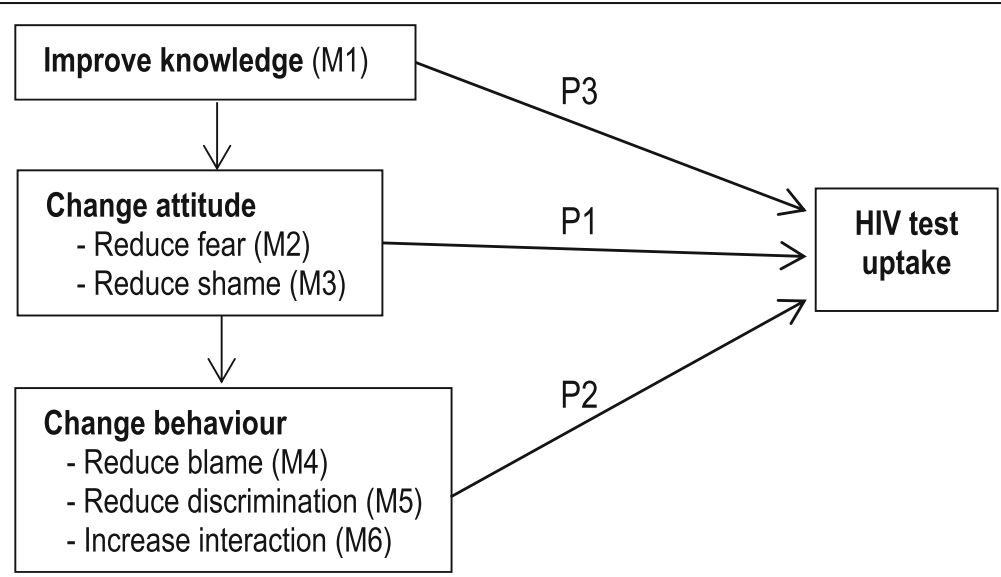

Fig. 4 Pathways for stigma reduction in terms of HIV test uptake 
activities, magazine-based information dissemination and distributing posters) and facilitated the formation of active community radio groups to increase awareness (M1). In addition, both interventions were complemented by national HIV testing programmes (Context; is abbreviated as ' $\mathrm{C}$ '). In Africa, the HIV-related health care system $(C)$, via increasing people's access to health care and providing HIV prevention messages, has been independently changing community knowledge (M1) and attitudes (M2), and normalizing HIV testing uptake (Outcome; is abbreviated as ' $\mathrm{O}$ ') [44].

\section{Reduced fear}

Interventions promoting home-based testing and counselling in several African countries ensured confidentiality in relation to testing and keeping the HIV status a secret which reduced people's fear of unwanted disclosure (M2) and led to an increased level of participation in HIV testing services $(O)[10,27,41]$. Contrastingly, in a community setting, most people might not consider having an HIV test because of fear associated with the lack of confidentiality [44]. Semugoma et al. (2012) described that, in a few African countries including Uganda, anti-homosexuality laws $(C)$ had a negative effect on stigma reduction and HIV test uptake among men having sex with men (MSM) and the transgender population because of a perceived threat of disclosure of sexual behaviour and criminalization [26]. In addition, the mandatory reporting of a positive HIV test report policy $(\mathrm{C})$ exacerbated the perceived threat of unwanted disclosure and discrimination and led to a lower uptake of HIV testing services among at-risk populations and the general population $(\mathrm{O})[26]$.

Laws that promote mandatory reporting of HIV information $(\mathrm{C})$ could lead to exacerbating fear of unwanted disclosure of HIV status. Working in South Africa, Weighs et al. reported that, in a workplace where HIV is stigmatized, an intervention that provided support via providing incentives for HIV testing was reported effective to increase knowledge, reduce fear and increase HIV testing uptake (Pathway 1) [45]. People who were tested due to the influence of an incentive were more likely to report a lower level of fear associated with HIV testing $[37,46]$. These interventions could be more effective in a context where the laws and health care practices promote full rights of PLWH to maintain the confidentiality of all the information associated with HIV infection [47].

\section{Reduced shame}

In South Africa, an intervention based on mobilizing local female counsellors ensured increased communication across different generations (M1), reduced shame (M3) for women to discuss sexual and HIV testing matters, and increased family support for those who tested positive [48]. Young girls and women in most African countries are generally ashamed to discuss sexual and HIV testing with parents and partners due to hierarchical relationships between generations, sexual taboos and intimate partner violence $(C)$ [41]. In addition, these young girls and women would feel more comfortable talking to female counsellors, as it is regarded culturally inappropriate for men to counsel women in the absence of the husband [48]. In addition, Massey (2012) reported that African women who perceive greater risk for HIV infection were more likely to hold less stigmatizing attitudes and test for HIV [35].

\section{Pathway 2: Knowledge and attitude lead to changes in stigmatizing behaviour and consequently, increase HIV test uptake}

Pathway 2 indicates the role of behavioural mechanisms to reduce discriminations among PLWH and consequently, increase HIV test uptake among at-risk or vulnerable populations. Seven interventions were found to follow Pathway 2 [28, 43-45, 48-50]. Three of the 7 were conducted in South Africa, 1 in Cambodia, 1 in Thailand, 1 in Mexico and 1 was a multi-country intervention (see Table 3). Two interventions conducted in South Africa aimed to mobilize local counsellors for counselling and HIV testing [44, 48]. Mobilizing local counsellors not only changed knowledge and attitudes but also the interventions triggered three behavioural mechanisms, namely, reduced blame (Mechanism 4; is abbreviated as 'M4'), reduced discrimination (Mechanism 5; is abbreviated as M5) and increased interaction with PLWH (Mechanism 6; is abbreviated as M6).

\section{Reduced blame}

Two interventions that mobilized traditional healers were effective in changing community misconceptions (M1), reducing the perceived threat of HIV (M2), reducing the tendencies to blame (M4) and excluding PLWH (M5) in South Africa. Consequently, these interventions increased HIV test uptake among at risk population groups and the general population $(\mathrm{O})[44,48]$.

Roura et al. (2009) and Moshabela et al. (2016) reported that, in some African communities, people believed that a wide array of diseases, including HIV, was caused by witches as a consequence of jealousy or revenge $[40,44]$. Because of traditional beliefs and practices, most people living or associated with HIV consulted traditional healers instead of health care workers [44]. Traditional beliefs and practices (C) about disease aetiology lead to blaming PLWH, which was one of the reasons why people who are at risk of HIV were avoiding HIV testing. The traditional healers were often associated with church, religious and prophetic forms of healing and were considered influential figures of 
authority and had the power to persuade the community (C) [44].

A participant from Tanzania (2008) put it this way [40],

In the past, the Sukuma called it "Kondela." A person slims and looks like s/he is HIV positive, but s/he is not. It's a disease similar to AIDS caused by medicines of the witches. It is often used if you quarrel with someone... if s/he has got that medicine s/he bewitches you.

\section{Reduced discrimination}

All four intervention studies that specifically targeted health care workers through awareness raising $[29,47,50,51]$ reported increases in knowledge; however, only three reported the interventions being effective to reduce the level of fear of transmission and discriminatory practices at health care facilities (e.g., reduced separating, labelling, marking in the records and giving nicknames; M5) and to increase health care workers' motivation to provide services to PLWH [47, 50, 51]. Another intervention conducted in Thailand that involved PLWH as a health care provider led to reduced discrimination in health care (M5) and increased participation of vulnerable populations in HIV testing services $(\mathrm{O})$. One of the participants from Thailand (2007) put it this way [49],

"The project encouraged PLWH to become involved in their community. In the intervention village, two previously undisclosed PLWH joined the project and disclosed their status to other villagers and were welcomed into the community project."

By contrast, the anti-homosexuality legislation in Uganda punished health care providers and families of MSM if they offered help and support of any kind, including HIV testing. This legislation reinforced a homophobic environment in the health care system and broader community $(\mathrm{C})$, and lead to fear and discrimination [26]. Based on the Ugandan experience, Semugoma (2012) noted that interventions aimed at reducing discrimination in a homophobic environment $(C)$ are less likely to be effective in terms of HIV test uptake.

\section{Increased interaction with PLWH}

Only two interventions implicated the mechanism of increased interaction with PLWH. For instance, in an intervention implemented in Thailand (2007), community leaders, youth volunteers and PLWH were involved together in identifying community needs, mobilizing community resources, generating additional income, and disseminating HIV/AIDS information in the community [49]. The intervention increased HIV knowledge (M1), increased interaction between PLWH (M6) and community people, and increased tolerance of PLWH in the community. Based on the experience from China, Wu et al. (2008) reported that engaging PLWH in delivering health care can also play a positive role to increase interactions between PLWH and the community people (M6), to increase knowledge about the situation of PLWH (M1) and to reduce discrimination in the community (M5) [47].

\section{Pathway 3: Knowledge leads to increases in HIV test uptake} without changing stigmatizing attitudes and behaviours

Four intervention studies reported increases in HIV test uptake due to the influence of knowledge but without any concomitant changes in stigmatizing attitudes and behaviours $[29,32,52,53]$. One of them was a film-based intervention based on the story of a heterosexual man in the context of Nigeria [32]. As the main male character in the film transmitted HIV to his fiancée via unprotected sex, this intervention had a positive effect on HIV testing uptake but a negative effect on changing the stigmatizing attitudes among Nigerian women [32]. A multi-country intervention study targeted PLWH, and the nurses reported increases in HIV test uptake without any reduction in the level of fear and perceived stigma [29].

In addition, one of these interventions was delivered in Kenya and reported changes in stigmatizing attitudes among community leaders (Pathway 2) but not among community members [52]. The increased HIV testing uptake among community members was due to a home-based testing approach without changing the stigmatizing attitudes. Based on the experience from China, $\mathrm{Ma}$ et al. (2008) reported that health care access also makes a difference in HIV test uptake, rather than other factors, such as stigma reduction [53]. It was also reported that some specific population groups, such as younger generations and people living in urban areas and having a higher income $(\mathrm{C})$, were more likely to have better HIV knowledge and test for HIV.

\section{Discussion}

Since the beginning of the epidemic, the majority of HIV prevention interventions have been based on awareness raising strategies [32]. Initially, these interventions only spread messages about HIV infection being linked with homosexual behaviour and drug use and defined HIV as an incurable, fatal and highly infectious disease. This message led to an increased level of perceived threat of HIV among the general population, which led to a negative evaluation of PLWH and created circumstances for exclusion and discrimination. On the other hand, there have been many achievements in the prevention and management of HIV, and the largest may be the development of highly active anti-retroviral therapy. Although HIV is no longer a fatal disease, HIV may not have been understood well by a considerable proportion of the 
population, and as a result, HIV stigma continues to persist in many communities.

Several behaviour-change models, such as the Knowledge-Attitude-Behaviour model and the Health Belief model, stipulate specific constructs and their relationships on how knowledge leads to changes in stigmatizing attitudes and behaviours [54]. These models, however, do not sufficiently consider contextual influences, which should still be described more comprehensively while addressing complex health behaviours, such as HIV test uptake. Our programme theory provides sufficient evidence to claim that knowledge is an essential component of stigma reduction. However, interventions aimed at increasing knowledge alone are insufficient to reduce stigma and lead to HIV test uptake.

Our review identifies some inhibiting pathways that influence the process of stigma reduction and HIV test uptake. The pathways, such as (a) anti-homosexuality laws leading to the creation of a homophobic environment at health care facilities, (b) traditional beliefs and practices about the disease aetiology leading to blame of PLWH, and (c) gender inequality that increases the feeling of shame among women while discussing HIV testing with their partner, increase stigmatizing attitudes and discourage people to test for HIV. Our review makes it clear why, how and for whom an awareness raising strategy should be complemented by other intervention strategies to change stigmatizing attitudes and behaviours, and consequently, increase HIV test uptake. Based on our programme theory, we propose the following points to be taken into account while designing and implementing an intervention to reduce stigma and increase HIV test uptake.

First, the interventions that are aimed at increasing HIV test uptake among at-risk or vulnerable populations should always take contextual factors into account. For instance, unless equal rights for MSM and the transgender population are ensured by law, stigma reduction interventions may not be effective to increase the participation of these specific population groups in HIV prevention. In this review, policies, such as anti-homosexuality laws and mandatory reporting of HIV test results, were found to create a homophobic environment with the health care system and broader community. Thus, policies, such as legal and social recognition of same-sex relationships or marriage and protection of sexual minority people from discrimination, should be implemented along with stigma reduction interventions to reduce stigma and increase HIV test uptake among the vulnerable and hard-to-reach population groups $[55,56]$.

Second, to increase the access of at-risk or vulnerable populations to HIV test uptake, it is important that the interventions followed Pathway 2 to trigger both attitudinal and behavioural mechanisms. Combination interventions having active community mobilizing strategies were more effective to reduce stigmatizing attitudes and behaviours and to increase HIV test uptake among at risk and vulnerable populations. The most consistently successful combination of strategies was awareness raising, health service provision and community mobilization strategies. Thus, our findings strongly support the concept of combination prevention, including biomedical (e.g., condoms, HIV testing), behavioural (e.g., awareness, counselling) and structural intervention strategies (e.g., decriminalization homosexuality, laws protecting PLWH), being more effective than individual prevention strategies [57].

Third, within the combination prevention approach, involving PLWH in providing health care was found to be promising to reduce discrimination. Involving PLWH in health care was found to have two major advantages. First, these PLWH directly benefitted from health care. Second, the networks initiated by these PLWH and vulnerable populations compared with the networks initiated by the HIV-negative general population were noted to be more effective to reduce fear, increase interaction of PLWH with other people and increase HIV test uptake [58]. Given that most of the developing countries are struggling to manage funds for the provision of routine HIV-related services, community mobilization strategies can still be implemented to increase awareness and encourage people to access health services for an effective and sustainable HIV/ AIDS response in resource-limited settings [59].

Fourth, extending HIV testing uptake and coverage to underserved and hard-to-reach populations that do not necessarily access an existing health care service can be challenging. These populations are more likely to fear identification by being specifically targeted by HIV-related health services [38, 39]. Our review revealed that one way to increase the access of these population groups to HIV-related health services (e.g., HIV testing) was via targeting a wide range of individuals in the community. In addition, we also learned that HIV testing uptake was increased to a greater extent when testing was offered at a non-clinical setting, such as home-based testing, compared to testing offered at a clinical setting, because of easy access and perceived confidentiality.

Last, the difference in stigma experiences and HIV test uptake between communities could partly be explained due to the difference in socio-economic status and partly due to the difference in health care access [53]. Therefore, in a resource-limited setting, incentives can also be an effective way of encouraging and rewarding vulnerable people for a positive behaviour. Studies on incentivized HIV testing interventions in several LMICs have identified improved HIV testing uptake among vulnerable populations $[60,61]$. In this review, we learned that incentives reduce the immediate logistical costs (e.g., 
transport and time) and the psychological costs (e.g., fear and stigma) in relation to HIV test uptake. Most importantly, in a resource-limited setting, the cost could be decreased by providing incentives as part of a lottery [45].

Stangl et al. (2013), in their review, have noted that the number, geography and complexity of stigma reduction interventions have expanded considerably, and, especially, a very high percentage of studies that showed reductions in stigma were of high quality [62]. However, they have also noted that most of these studies do not adequately address the manifestations of stigma on HIV test uptake. Our review also noted that data on interventions on stigma reduction and the influence of context on the intervention effectiveness to increase HIV test uptake are poorly documented. The data reported in some of the primary studies from where we had to pool insights were thin. Meaning that, the data were mostly descriptive, conceptually poor and had so little value for theorizing particularly on the context in which the interventions were rolled out. For instance, interventions based on regulatory law strategies are seldom implemented and tested for their impact on HIV test uptake, and limited literature currently exists on the link between structural factors and HIV test uptake. Therefore, in the future, researchers should be more motivated to consider why the stigma reduction intervention worked or did not work to increase HIV test uptake, and intervention studies on stigma reduction should pay more attention to the context to understand how the intervention worked.

\section{Limitations}

A key limitation of this realist review is that we were very specific to include only studies with stigma reduction components and published in English. We also did not attempt to perform an independent search for national-level grey literature in the websites of Governmental and non-governmental organizations. As a result, our review may have missed uncovering some other contextual factors and mechanisms. For example, Figures 3 and 4 only depict the mechanisms leading to positive change and there are several inhibitory pathways that we have discussed in the narratives. Thus, we propose that the mechanisms outlined in this review should be seen as the key, rather than the only, mechanisms contributing to stigma reduction and HIV test uptake. Additionally, because of the qualitative nature of our review method, we were unable to define the cut-off of behaviour change level achieved to explain which particular interventions or the components of the intervention were more effective.

Despite these limitations, the use of a realist review is increasingly relevant in view of the contextualization of the issues, i.e., HIV-related stigma, implementation of interventions in different settings and contexts, as well as the psychological core constructs that render such interventions effective, in particular in LMICs. The scope of the review was broad, and not limited to one region (e.g., Sub-Saharan Africa), which added value in trying to achieve a saturation point in the number of ideas presented in the primary studies. There were 21 intervention studies that come from Sub-Saharan Africa and the studies that come from outside Sub-Saharan Africa also validated what have been learned from the studies conducted in Africa.

In addition, we included and synthesized all types of studies (i.e., quantitative, qualitative and mixed-methods) providing information about interventions, contexts, mechanisms and outcomes, surrounding stigma reduction and HIV test uptake. In this way, the review of evidence brought together a comprehensive perspective in terms of interventions and populations to the analysis and synthesis. In light of implementation research, there is a great need to better understand the general mechanisms that make stigma reduction interventions effective, and subsequently to collect evidence that goes beyond the typical experimental designs, which are not always feasible due to the complexity of interventions and the contexts in which they are implemented. The programme theory can be transferable to other communities and across diverse populations.

\section{Conclusion}

The refined programme theory resulting from the realist review clarified why, how and under what circumstances interventions having singular or combination strategies are effective across different population groups. We found that these interventions produce an effect through two major pathways: (a) knowledge leads to changes in stigmatizing attitudes and increases in HIV test uptake, and (b) knowledge and attitude lead to changes in stigmatizing behaviours and consequently lead to HIV test uptake. In addition, this programme theory supports the adaptation of intervention strategies in terms of the socio-structural and cultural context and the population being targeted to reduce stigma and increase HIV test uptake in LMICs.

\section{Abbreviations \\ ART: Anti-retroviral treatment; CMO: Context-Mechanism-Outcome Configurations; HBCT: Home-based HIV Counselling and Testing;" HIV/ AIDS: Human immunodeficiency virus and Acquired immune deficiency syndrome; M1: Mechanism 1; M2: Mechanism 2; M3: Mechanism 3; M4: Mechanism 4; M5: Mechanism 5; M6: Mechanism 6; MSM: Men having sex with men;" P1: Pathway 1; P2: Pathway 2; P3: Pathway 3; PLWH: People living with HIV; PMTCT: Prevention of Mother to Child Transmission of HIV; RCT: Randomized controlled trial; UNAIDS: Joint United Nations Program on HIV/AIDS; VCT: voluntary counselling and testing; WHO: World Health Organization}

\section{Acknowledgements}

Authors would like to acknowledge members of Academic Centre for General Practice, KU Leuven, Belgium for their help and support during the study. 


\section{Funding}

This study received no specific grant from any funding agency in the public, commercial, or not-for-profit sectors.

\section{Availability of data and materials}

The supplementary data extraction tools are already published elsewhere $[8,63]$. The summary table and coding tree has been made available in this article. The other materials can be made available upon request.

\section{Authors' contributions}

$\mathrm{ST}, \mathrm{KH}, \mathrm{MC}, \mathrm{AB}$ and $\mathrm{CM}$ conceived the original research idea and led the design of the study. ST, SP, SD and CM conducted the screening of the papers. ST and CM conducted the data extraction and ST, $\mathrm{KH}, \mathrm{MC}$ and $\mathrm{CM}$ conducted the analysis. $\mathrm{KH}, \mathrm{MC}, \mathrm{AB}, \mathrm{SP}, \mathrm{SD}$ and $\mathrm{CM}$ provided insights in the final program theory. ST developed the first draft of the article. $\mathrm{KH}, \mathrm{MC}, \mathrm{AB}, \mathrm{SP}, \mathrm{SD}$ and $\mathrm{CM}$ oversaw the development and revision of the article and contributed to the revisions. All authors reviewed and approved the final draft

\section{Ethics approval and consent to participate}

Not applicable.

\section{Consent for publication}

Not applicable.

\section{Competing interests}

The authors declare that they have no competing interests.

\section{Publisher's Note}

Springer Nature remains neutral with regard to jurisdictional claims in published maps and institutional affiliations.

\section{Author details}

${ }^{1}$ Research Unit of General Practice, Department of Public Health, University of Southern Denmark, Odense 5000, Denmark. ${ }^{2}$ Social Research Methodology Group, Faculty of Social Sciences, KU Leuven, Parkstraat 45, 3000 Leuven, Belgium. ${ }^{3}$ Health Research Institute, University of Canberra, University Drive, 22-B17, Bruce, ACT 2601, Australia. ${ }^{4}$ Department of Public Health, Institute of Tropical Medicine, Nationalestraat 155, 2000 Antwerp, Belgium. ${ }^{5}$ Department of Public Health and Primary care, KU Leuven, Kapucijnenvoer 33, 3000 Leuven, Belgium.

Received: 10 January 2018 Accepted: 26 October 2018

\section{Published online: 20 November 2018}

\section{References}

1. Unaids. Global AIDS Update 2016. Geneva, Switzerland: UNAIDS; 2016.

2. UNAIDS: Prevention Gap Report. In.; 2016.

3. Golub SA, Gamarel KE. The impact of anticipated HIV stigma on delays in HIV testing behaviors: findings from a community-based sample of men who have sex with men and transgender women in new York City. AIDS Patient Care STDs. 2013;27(11):621-7.

4. Unaids: UNAIDS fact sheet on stigma and discrimination. In.; 2003.

5. Latalova K, Kamaradova D, Prasko J. Perspectives on perceived stigma and self-stigma in adult male patients with depression. Neuropsychiatr Dis Treat. 2014;10:1399-405.

6. Scambler G. Health-related stigma. Sociol. Health IIIn. 2009;31(3):441-55.

7. Thapa S, Hannes K, Buve A, Bhattarai S, Mathei C. Theorizing the complexity of HIV disclosure in vulnerable populations: a grounded theory study. BMC Public Health. 2018;18(1):162.

8. Thapa S, Hannes K, Cargo M, Buve A, Aro AR, Mathei C. Building a conceptual framework to study the effect of HIV stigma-reduction intervention strategies on HIV test uptake: a scoping review. J Assoc Nurses AIDS Care. 2017;28(4):545-60

9. Kimaiyo S, Were MC, Shen C, Ndege S, Braitstein P, Sidle J, Mamlin J: Homebased HIV counselling and testing in western Kenya. East Afr Med J. 2010; 87(3):100-8.

10. Jurgensen M, Sandoy IF, Michelo C, Fylkesnes K, Group ZS. Effects of homebased voluntary counselling and testing on HIV-related stigma: findings from a cluster-randomized trial in Zambia. Soc Sci Med. 2013;81:18-25.
11. Hutchinson PL, Mahlalela X, Yukich J. Mass media, stigma, and disclosure of HIV test results: multilevel analysis in the eastern cape, South Africa. AIDS Educ Prev. 2007;19(6):489-510.

12. Pawson R, Tilley N: Realistic evaluation: sage; 1997.

13. Stangl AL, Grossman Cl. Global Action to reduce HIV stigma and discrimination. J Int AIDS Soc. 2013;16(3(Suppl 2):18934.

14. Pawson R, Greenhalgh T, Harvey G, Walshe K. Realist review--a new method of systematic review designed for complex policy interventions. J Health Serv Res Policy. 2005;10 Suppl 1(1355-8196 (Print)):21-34.

15. Triana R: Evidence-based policy: a realist perspective, by ray Pawson. In, vol. 7; 2008: 321-323.

16. Merton RK. Social theory and social structure. New York: The free press; 1968

17. Thornicroft G, Rose D, Kassam A, Sartorius N. Stigma: ignorance, prejudice or discrimination? Br J Psychiatry. 2007;190:192-3.

18. Benoot C, Hannes K, Bilsen J. The use of purposeful sampling in a qualitative evidence synthesis: a worked example on sexual adjustment to a cancer trajectory. BMC Med Res Methodol. 2016;16(1):21.

19. Durham J, Bains A. Research protocol: a realist synthesis of contestability in community-based mental health markets. Syst Rev. 2015;4(1):32.

20. Rycroft-Malone J, McCormack B, Hutchinson AM, DeCorby K, Bucknall TK, Kent B, Schultz A, Snelgrove-Clarke E, Stetler CB, Titler M, et al. Realist synthesis: illustrating the method for implementation research. Implement Sci. 2012;7:33

21. Souto RQ, Khanassov V, Hong QN, Bush PL, Vedel I, Pluye P. Systematic mixed studies reviews: updating results on the reliability and efficiency of the mixed methods appraisal tool. Int J Nurs Stud. 2015;52(1):500-1.

22. Brown HE, Atkin AJ, Panter J, Corder K, Wong G, Chinapaw MJ, van Sluijs E. Family-based interventions to increase physical activity in children: a metaanalysis and realist synthesis protocol. BMJ Open. 2014;4(8):e005439.

23. Mukolo A, Blevins M, Victor B, Paulin HN, Vaz LM, Sidat M, Vergara AE. Community stigma endorsement and voluntary counseling and testing behavior and attitudes among female heads of household in Zambezia Province, Mozambique. BMC public health. 2013;13:1155

24. Chung AH, Rimal RN. Revisiting the importance of knowledge: from Namibia, a case for promoting knowledge by campaigns to reduce stigma. Health Educ Behav. 2015:42(2):249-56.

25. Maughan-Brown B, Nyblade L. Different dimensions of HIV-related stigma may have opposite effects on hiv testing: evidence among young men and women in South Africa. AIDS Behav. 2014;18(5):958-65.

26. Semugoma P, Beyrer C, Baral S. Assessing the effects of anti-homosexuality legislation in Uganda on HIV prevention, treatment, and care services. SAHARA J. 2012;9(3):173-6.

27. Coates TJ, Kulich M, Celentano DD, Zelaya CE, Chariyalertsak S, Chingono A, Gray G, Mbwambo JK, Morin SF, Richter L, et al. Effect of community-based voluntary counselling and testing on HIV incidence and social and behavioural outcomes (NIMH project accept; HPTN 043): a clusterrandomised trial. Lancet Glob Health. 2014;2(5):e267-77.

28. Maman S, van Rooyen H, Stankard P, Chingono A, Muravha T, Ntogwisangu J, Phakathi Z, Srirak N, FM S, team NPAs. NIMH project accept (HPTN 043): results from in-depth interviews with a longitudinal cohort of community members. PLoS One. 2014;9(1):e87091.

29. Uys L, Chirwa M, Kohi T, Greeff M, Naidoo J, Makoae L, Dlamini P, Durrheim K, Cuca Y, Holzemer WL. Evaluation of a health setting-based stigma intervention in five African countries. AIDS Patient Care STDs. 2009;23(12):1059-66.

30. Berendes S, Rimal RN. Addressing the slow uptake of HIV testing in Malawi: the role of stigma, self-efficacy, and knowledge in the Malawi BRIDGE project. J Assoc Nurses AIDS Care. 2011;22(3):215-28.

31. Chung AHR, R. N. Revisiting the importance of knowledge: from Namibia, a case for promoting knowledge by campaigns to reduce stigma. Health Educ Behav. 2015:42(2):249-56.

32. Lapinski MK, Nwulu P. Can a short film impact HIV-related risk and stigma perceptions? Results from an experiment in Abuja, Nigeria. Health Commun. 2008;23(5):403-12

33. Pappas-DeLuca KA, Kraft JM, Galavotti C, Warner L, Mooki M, Hastings P, Koppenhaver T, Roels TH, Kilmarx PH. Entertainment-education radio serial drama and outcomes related to HIV testing in Botswana. AIDS Educ Prev. 2008;20(6):486-503.

34. Young SD, Hlavka Z, Modiba P, Gray G, Van Rooyen H, Richter L, Szekeres G, Coates T. HIV-related stigma, social norms, and HIV testing in Soweto and Vulindlela, South Africa: National Institutes of mental health project accept (HPTN 043). J Acquir Immune Defic Syndr. 2010;55(5):620-4. 
35. Massey PM, Prelip M, Rideau A, Glik DC. School-based HIV prevention in Dakar, Senegal: findings from a peer-led program. Int Q Community Health Educ. 2012;33(2):129-41.

36. Pulerwitz J, Michaelis A, Weiss E, Brown L, Mahendra V. Reducing HIV-related stigma: lessons learned from horizons research and programs. Public Health Rep. 2010;125(2):272-81.

37. Chefranova lu A, Petranovskaia MR, Khodakova VI. Disinfecting effect of ammonia on the eggs of helminths (Trichocephalus muris and Diphyllobothrium latum) and enterobacteria. Med Parazitol (Mosk). 1978;47(1):99-101.

38. Castro A, Farmer P. Understanding and addressing AIDS-related stigma: from anthropological theory to clinical practice in Haiti. Am J Public Health. 2005;95(1):53-9.

39. Jurgensen M, Sandoy IF, Michelo C, Fylkesnes K, Mwangala S, Blystad A: The seven Cs of the high acceptability of home-based VCT: results from a mixed methods approach in Zambia. Soc Sci Med 2013, 97(1873-5347 (Electronic)): 210-219.

40. Roura M, Urassa M, Busza J, Mbata D, Wringe A, Zaba B. Scaling up stigma? The effects of antiretroviral roll-out on stigma and HIV testing. Early evidence from rural Tanzania. Sex Transm Infect. 2009;85(4):308-12.

41. van Rooyen H, Essack Z, Rochat T, Wight D, Knight L, Bland R, Celum C. Taking HIV Testing to Families: Designing a Family-Based Intervention to Facilitate HIV Testing, Disclosure, and Intergenerational Communication. Front Public Health. 2016;4(2296-2565 (Linking)):154.

42. Mall S, Middelkoop K, Mark D, Wood R, Bekker LG. Changing patterns in HIV/AIDS stigma and uptake of voluntary counselling and testing services: the results of two consecutive community surveys conducted in the Western cape, South Africa. Aids Care. 2013;25(2):194-201.

43. White J, Delvaux T, Chhea C, Saramony S, Ouk V, Saphonn V. The linked response: lessons emerging from integration of HIV and reproductive health Services in Cambodia. AIDS Res Treat. 2013;2013:504792.

44. Moshabela M, Zuma T, Orne-Gliemann J, Iwuji C, Larmarange J, McGrath N, Group ATS. "It is better to die": experiences of traditional health practitioners within the HIV treatment as prevention trial communities in rural South Africa (ANRS 12249 TasP trial). Aids Care. 2016;28 Suppl 3(1360-0451 (Electronic)):24-32.

45. Weihs M, Meyer-Weitz A. A lottery incentive system to facilitate dialogue and social support for workplace HIV counselling and testing: a qualitative inquiry. SAHARA J. 2014;11(1):116-25.

46. Weiser SD, Heisler M, Leiter K, Percy-de Korte F, Tlou S, DeMonner S, Phaladze N, Bangsberg DR, lacopino V. Routine HIV testing in Botswana: a population-based study on attitudes, practices, and human rights concerns. PLoS Med. 2006:3(7):e261.

47. Wu S, Li L, Wu Z, Liang LJ, Cao H, Yan Z, Li J. A brief HIV stigma reduction intervention for service providers in China. AIDS Patient Care STDs. 2008 22(6):513-20.

48. Doherty T, Tabana H, Jackson D, Naik R, Zembe W, Lombard C, Swanevelder S, Fox MP, Thorson A, Ekstrom AM, et al. Effect of home based HIV counselling and testing intervention in rural South Africa: cluster randomised trial. BMJ. 2013:346:f3481.

49. Apinundecha C, Laohasiriwong W, Cameron MP, Lim S. A community participation intervention to reduce HIV/AIDS stigma, Nakhon Ratchasima province, Northeast Thailand. AIDS Care. 2007;19(9):1157-65.

50. Colchero MA, Bautista-Arredondo S, Cortés-Ortiz MA, Romero-Martinez M, Salas J, Sosa-Rubí SG, Uribe P. Impact and economic evaluations of a combination prevention programme for men who have sex with men in Mexico. AIDS. 2016;30(2):293-300.

51. Pulerwitz J, Oanh KT, Akinwolemiwa D, Ashburn K, Nyblade L. Improving hospital-based quality of care by reducing HIV-related stigma: evaluation results from Vietnam. AIDS Behav. 2015;19(2):246-56.

52. Low C, Pop-Eleches C, Rono W, Plous E, Kirk A, Ndege S, Goldstein M, Thirumurthy $\mathrm{H}$. The effects of home-based HIV counseling and testing on HIV/AIDS stigma among individuals and community leaders in western Kenya: evidence from a cluster-randomized trial. AIDS Care. 2013;25(Suppl 1):S97-107.

53. Ma W, Wu Z, Qin Y, Detels R, Shen L, Li Y, Liu T, Chen F. A comparison of voluntary counseling and testing uptake between a China CARES county and a county not designated for the China CARES program. AIDS Patient Care STDs. 2008;22(6):521-33.

54. Kaufman MR, Cornish F, Zimmerman RS, Johnson BT. Health behavior change models for HIV prevention and AIDS care: practical recommendations for a multi-level approach. J Acquir Immune Defic Syndr. 2014;66 Suppl 3(Suppl 3):S250-8.
55. Meyer $\mathbb{H}$, Bayer R. School-based gay-affirmative interventions: first amendment and ethical concerns. Am J Public Health. 2013;103(10):1764-71.

56. Buffie WC. Public health implications of same-sex marriage. Am J Public Health. 2011;101(6):986-90.

57. Hankins CA, de Zalduondo BO. Combination prevention: a deeper understanding of effective HIV prevention. AIDS (London, England). 2010; 24(Suppl 4):S70-80.

58. McCoy SI, Shiu K, Martz TE, Smith CD, Mattox L, Gluth DR, Murgai N, Martin M, Padian NS. Improving the efficiency of HIV testing with peer recruitment, financial incentives, and the involvement of persons living with HIV infection. J Acquir Immune Defic Syndr. 2013:63(2):e56-63.

59. Parker R, Aggleton P. HIV and AIDS-related stigma and discrimination: a conceptual framework and implications for action. Soc Sci Med. 2003;57(1):13-24

60. Nglazi MD, van Schaik N, Kranzer K, Lawn SD, Wood R, Bekker LG. An incentivized HIV counseling and testing program targeting hard-to-reach unemployed men in Cape Town, South Africa. J Acquir Immune Defic Syndr. 2012;59(3):e28-34

61. Lee R, Cui RR, Muessig KE, Thirumurthy H, Tucker JD. Incentivizing HIV/STI testing: a systematic review of the literature. AIDS Behav. 2014;18(5):905-12.

62. Stangl AL, Lloyd JK, Brady LM, Holland CE, Baral S. A systematic review of interventions to reduce HIV-related stigma and discrimination from 2002 to 2013: how far have we come? J Int AIDS Soc. 2013:16(3 Suppl 2):18734.

63. Thapa S, Hannes K, Cargo M, Buve A, Mathei C. Effect of stigma reduction intervention strategies on HIV test uptake in low- and middle-income countries: a realist review protocol. Syst Rev. 2015;4(2046-4053 (Electronic)):142.

\section{Ready to submit your research? Choose BMC and benefit from:}

- fast, convenient online submission

- thorough peer review by experienced researchers in your field

- rapid publication on acceptance

- support for research data, including large and complex data types

- gold Open Access which fosters wider collaboration and increased citations

- maximum visibility for your research: over $100 \mathrm{M}$ website views per year

At BMC, research is always in progress.

Learn more biomedcentral.com/submissions 